\title{
Load Bearing and Deformation Characteristics of Granular Spoils under Unconfined Compressive Loading for Coal Mine Backfill
}

\author{
Guodong Li, Shugang Cao, Yong Li, and Zhenyu Zhang \\ State Key Laboratory of Coal Mine Disaster Dynamics and Control, Chongqing University, Chongqing 400044, China \\ Correspondence should be addressed to Shugang Cao; caosg@cqu.edu.cn
}

Received 26 September 2015; Revised 15 December 2015; Accepted 27 December 2015

Academic Editor: Dimitrios G. Aggelis

Copyright (C) 2016 Guodong Li et al. This is an open access article distributed under the Creative Commons Attribution License, which permits unrestricted use, distribution, and reproduction in any medium, provided the original work is properly cited.

\begin{abstract}
The load bearing capacity and deformation response of granular spoils under uniaxial compression are numerically and experimentally investigated, aiming to shed light on the performance of back filled waste spoils while controlling ground subsidence after coal extraction. In numerical study, the particles are assembled in PFC commercial code in light of the digitized real shape of spoils with image technique, which is proved to be consistent with the physical test. The results from numerical and laboratory experiments showed that the complete compressive process of spoils tended to have spatial and temporal characteristics. The loadstrain curves of investigated specimens could be divided into three stages (stage I, rearranging stage; stage II, breaking stage; stage III, consolidating stage) and three zones (I, rearranging zone; II, interlocking zone; III, consolidated zone) from outside to inside. During stage I, the load increasing rate of smaller spoils is relatively low, but it increases faster than larger ones in stages II and III. In addition, spoils with Talbot's gradation are greater than single gradations. The magnitude of the density in consolidated zone is maximum, indicating that it is the main part holding the overlying strata weight.
\end{abstract}

\section{Introduction}

For underground coal mining, piles of granular spoils with irregular shapes and varied size are produced due to coal extraction, which consists of debris and waste rock materials. Conventionally, spoils are heaped up on ground surface, which not only occupies a certain amount of land, but also causes environmental pollution [1]. To some extent, this makes the coal mining practice under strict public scrutiny. To solve such a problem and ensure the mining license in some countries, the most direct and effective way is to reuse them as supporting material to backfill the excavated strata. The utilization of gangue mitigates negative impact on environment; on the other hand, backfilled spoils can reduce the cave-in of roof strata and control ground subsidence. However, the deformation and breakage of spoils under compression are distinctly different from fractured rock mass.

So far, many research efforts have been made to investigate the compaction characteristics of rock spoil. Michalski and Skarzynska [2] and Solesbury [3] found that the rock experienced crushing, compacting, secondary crushing, and compacting during compressing. Jiang et al. [4] and Qian et al. [5] divided the compressing process of coal waste into crushing stage and compacting stage. In addition, they carried out experimental study on confined loading-water immersion-unloading of coal spoil. Using the largest shear box, Lee et al. [6] analysed the factors that affected the stress-strain characteristics of crushed rock, including maximum grain size, density, degree of saturation, uniformity coefficient, and particle breakage. Su et al. [7] analysed the effects of rock strength, particle size, and compaction stress on compression characteristics of spoils. Ma et al. [8] experimentally studied creep behaviour of saturated disaggregated sandstones to study the time-dependent behaviours of disaggregated rocks in underground mining conditions. Besides, Miao et al. [9], Zhang [10], and Zhang et al. [11] conducted experimental and theoretical studies on broken expansion and compaction properties of crushed rock spoil.

The existing studies are mainly based on compression tests. The spoils are compacted in steel cylinder during 


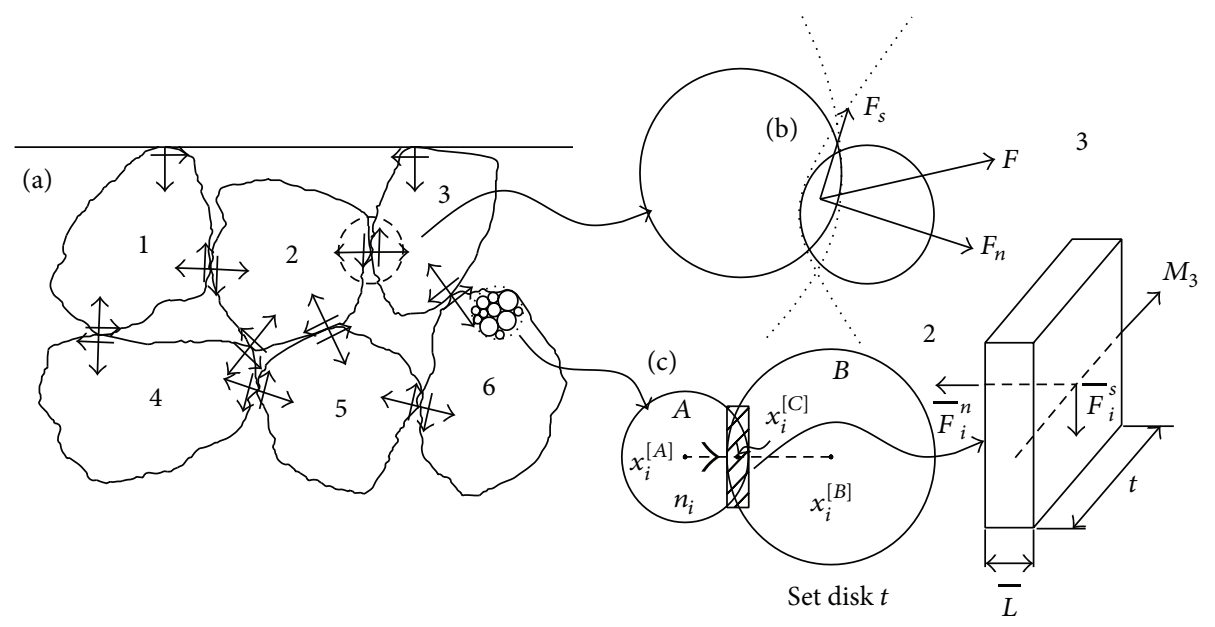

FIGURE 1: The contact constitutive models of spoils: (a) the compression test model; (b) the unbonded model; (c) the parallel bonded model.

the test. Since the value of elastic modulus of steel cylinder is great, the lateral movement or deformation of aggregated spoils is constrained during compaction. In this situation, the boundary condition applies to the spoils that can be deemed approximately as displacement constraint. Under this boundary condition, the interaction between spoils is strengthened. Accordingly, the breakage and load-carrying properties are overestimated. Unlikely, during the backfilling mining process of goaf, the boundary condition is weak when compared with the above test.

In order to investigate the mechanical properties, crushing and splitting of spoils had different gradation and particle sizes without lateral constraint. In this research, the unconfined compaction tests of spoils were carried out. To this end, PFC numerical modelling and laboratory tests were conducted to investigate the mechanical behaviour and breakage of spoils under unconfined compression. Firstly, the numerical modelling technique and results were present in Section 2. Then the details of laboratory tests and results were given in Section 3. Later on, the comparison and discussion of numerical and experimental results are conducted to conclude the mechanical response of spoils without lateral confinement and revealed its performance as the backfilling material in goaf of coal mine.

\section{The Unconfined Compression}

2.1. Theory of PFC. Here, commercial code, PFC, is used to numerically investigate the uniaxial compressive characteristics of granular spoils under unconfined crushing. PFC is based on the microscopic discrete element theory to simulate the movement and interaction of particles and it is capable of simulating irregular shaped particles for the analysis of rock mechanics problems. The PFC has been extensively used to study a wide range of rock mechanical phenomena [12-16]. As illustrated by Potyondy and Cundall [17] and Potyondy [18] such modelling approach can capture and simulate many aspects of the mechanical behaviour and failure processes of brittle rock from the laboratory to rock mass scale.
2.2. Macro- and Microproperties. There are two types of contact in loose spoils: one is in for the fraction effect between spoils as illustrated in Figure 1(b); the other is for the contact among particles which assembles spoils (Figure 1(c)). In numerical modelling, these two kinds of contacts should be treated differently.

In PFC, the contact constitutive model of unbonded material is as follow:

$$
\begin{aligned}
& \bar{F}_{n}=k_{n} \cdot \bar{U}_{n}, \\
& \bar{F}_{s}=k_{s} \cdot \bar{U}_{s},
\end{aligned}
$$

where $\bar{F}_{n}, \bar{F}_{s}$ are the normal and shear force; $k_{n}, k_{s}$ are the normal and shear stiffness; $\bar{U}_{n}, \bar{U}_{s}$ are the normal and shear overlap.

Such material is normally used to describe particles without bonds, for example, sand, grain, and crushing rock. On the macroscale, the spoils are discrete and unbonded. Therefore, the unbonded material is chosen to define the contact constitutive relation among spoils.

The parallel-bonded model describes the mechanical behaviour of a finite-sized piece of cementation material deposited between two balls, which can transmit both forces and moments among particles. The total force and moment associated with the parallel bond are denoted by $\bar{F}_{i}$ and $\bar{M}_{i}$, with the convention that this force and moment represent the action of bond on particle $B$. The force vector can be decomposed into normal and shear parts as

$$
\bar{F}_{i}=\bar{F}_{n i}+\bar{F}_{s i}
$$

where $\bar{F}_{n i}$ and $\bar{F}_{s i}$ denote the normal and shear component vectors, respectively (Figure 1(c)).

When the bond is formed, $\bar{F}_{i}$ and $\bar{M}_{i}$ are initialized to zero. Each subsequent relative displacement and rotation increment at the contact results in the increment of elastic force and moment that is added to the current values. The 


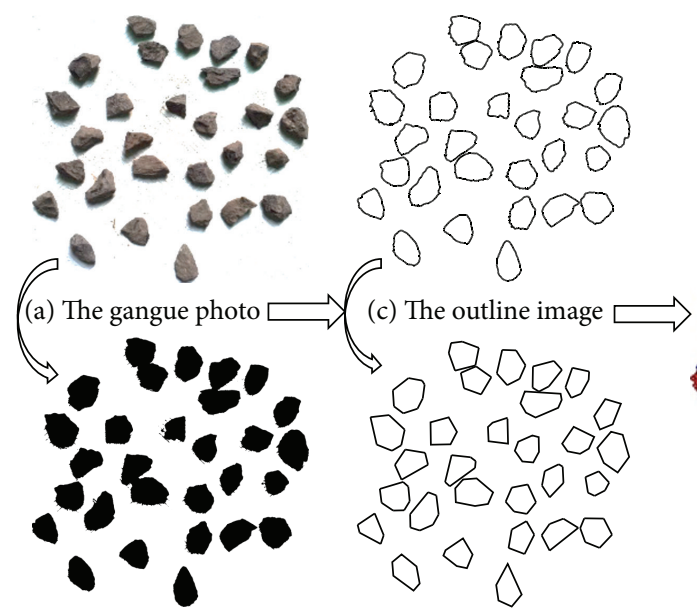

(b) The binary image (d) The simplified silhouette image

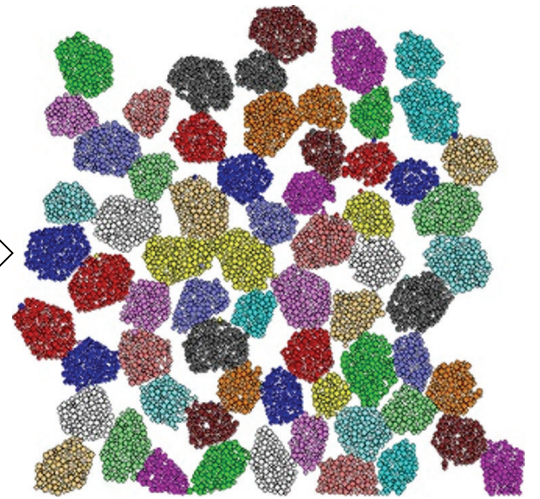

(e) The numerical model

FIGURE 2: The modelling processes of spoils.

elastic force increments over a time step of $\Delta t$ are calculated by

$$
\begin{aligned}
\Delta \bar{F}_{n i} & =\left(-\bar{k}_{n} A \Delta U_{n}\right) n_{j}, \\
\Delta \bar{F}_{s i} & =-\bar{k}_{s} A \Delta U_{s t}, \\
\Delta U_{t} & =v_{t} \Delta t, \\
\Delta \bar{M}_{i} & =-\bar{k}_{s} I \Delta \theta_{3}, \\
\Delta \theta_{3} & =\left(\omega_{3}^{[B]}-\omega_{3}^{[A]}\right) \Delta t,
\end{aligned}
$$

where $v_{i}$ is the contact velocity; $A$ is the area of the bond cross section; $I$ is the moment of inertia of the bond cross section about an axis through the contact point and in the direction of $\theta_{3} ; \omega_{3}^{[\chi]}$ is the rotational velocity of the wall with respect to $x_{i}^{[\chi]}$ the centre of rotation of the ball; $\bar{k}_{n}, \bar{k}_{s}$ are the normal and shear stiffness at the contact; $\Delta U_{n}$ is the overlap which is defined to be the relative contact displacement in the normal direction; $\Delta U_{s}$ is the shear component of the contact displacement increment; $n_{j}$ is the unit normal.

The new force and moment vectors associated with the parallel bond are found by summing the old values existing at the start of the time step with the elastic force and moment increment vectors. The new force vectors are calculated by

$$
\begin{aligned}
& \bar{F}_{n i} \longleftarrow \bar{F}_{n} n_{j}+\Delta \bar{F}_{n i}, \\
& \bar{F}_{s i} \longleftarrow \bar{F}_{s i}+\Delta \bar{F}_{s i}, \\
& \bar{M}_{i} \longleftarrow \bar{M}_{i}+\Delta \bar{M}_{i} .
\end{aligned}
$$

According to the Beam Theory, the maximum normal stress $\sigma_{\max }$ and shear stress $\tau_{\max }$ acting on the bond periphery are calculated to be

$$
\begin{aligned}
\sigma_{\max } & =\frac{-\bar{F}_{n}}{A}+\frac{\left|\bar{M}_{i}\right|}{I} \bar{R}, \\
\tau_{\max } & =\frac{\left|\bar{F}_{s i}\right|}{A} .
\end{aligned}
$$

TABLE 1: Values of microparameters of granular spoils.

\begin{tabular}{lccccc}
\hline $\begin{array}{l}R_{\max } \\
\mathrm{mm}\end{array}$ & $\begin{array}{c}R_{\min } \\
\mathrm{mm}\end{array}$ & $\begin{array}{c}k_{n} \\
\mathrm{GPa}\end{array}$ & $k_{n} / k_{s}$ & $\begin{array}{c}\bar{k}_{n} \\
\mathrm{GPa}\end{array}$ & $\bar{k}_{n} / \bar{k}_{s}$ \\
\hline 6.5 & 3.3 & 11 & 1.25 & 10 & 1 \\
\hline
\end{tabular}

If the maximum tensile stress exceeds the normal strength $\left(\sigma_{\max }>\bar{\sigma}_{c}\right)$ or the maximum shear stress exceeds the shear strength $\left(\tau_{\max }>\bar{\tau}_{c}\right)$, the parallel bond breaks. For a single spoil, it is constituted by a large amount of particles with normal and shear stiffness, so the parallel bond is used to describe the contact constitutive relation of spoil.

In order to assess the validity of the proposed model parameters, the calibration process should be performed. For purpose of parameters calibrating, random packing particles were generated within a rectangular container. Such sample was used for PFC simulations under a typical experiment condition. Then the parameters of model were modified to match the macroscopic mechanics of the rock, for example, stress-strain curve, the peak stress, and Young's modulus. After calibration, the parameters can be acquired, as shown in Table 1 , where $R_{\max }$ and $R_{\min }$ represent for the maximum and minimum size of particle; $k_{n}$ and $k_{s}$ are the modulus of particle; the $\bar{k}_{n}$ and $\bar{k}_{s}$ are the modulus of parallel bond.

2.3. Numerical Simulation of Unconfined Compaction. The shape of spoils is irregular polygon shapes, and interlocking of fragments is the main part bearing axial loading. It is important for simulation to construct model whose shape is consistent with real spoils'. To model the mechanics behaviour of the waste spoils as the backfilling material, pictures of fragments were firstly taken in laboratory (Figure 2(a)); then the chrominance information of the picture was used for image binarization (Figure 2(b)); after extracting the profile information of spoils from binary image by using image processing software, it was imported into AutoCAD (Figure 2(c)). In this simulation, the particle size of 16-20 mm was taken as case study. 


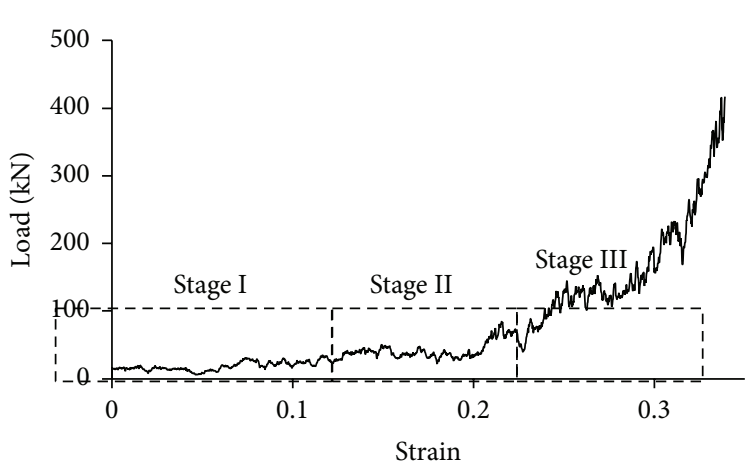

(a)

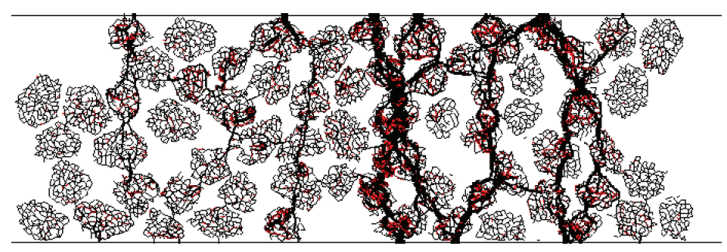

(c)

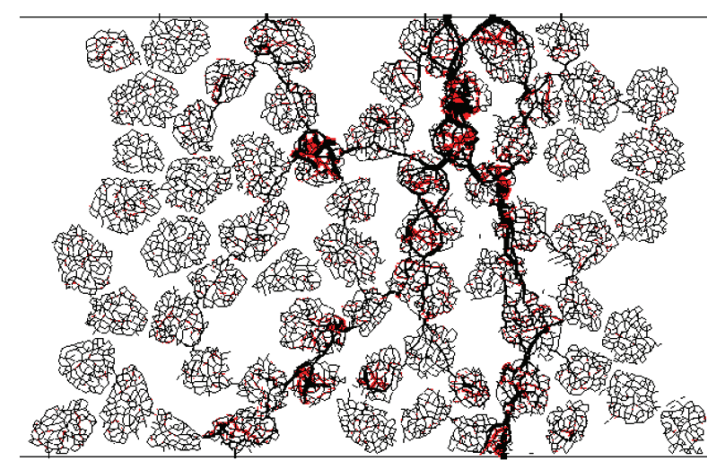

(b)

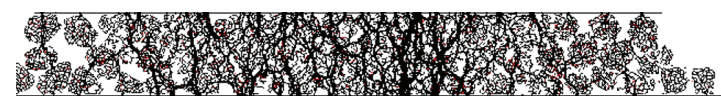

(d)

FIGURE 3: The mechanical properties of spoils: (a) load-strain curve of spoils under unconfined compression; (b-d) the distribution force chains in spoils during different compressing stages.

The walls are often used as boundaries in PFC, for one fragment; if the boundary of model is a smooth curve, many short straight walls should be used to reproduce the profile. During the model construction, stochastic polygons (the number of edges of polygons are 4-8) are used as the simplified outlines of spoils (Figure $2(\mathrm{~d})$ ). The digitized coordinate of simplified outlines was then exported from AutoCAD to generate boundary walls in PFC code. The particles were then created and separated at low speeds through fish function in polygons. After extending the volume, the enclosing wall will be filled with particles under specified porosity. Finally, floaters are deleted. Since the number of particles dramatically limits the computation speed and the calibration process needs repeated calculation, it is time consuming to reach static equilibrium if the model contains too many particles. Moreover, in order to acquire clear breakage of spoils, the ratio of width and diameter of sample and spoils should be relatively large. The numerical model in this research is shown in Figure 2(e).

After the model construction, spoils were freely settled and then compressed by the wall. The velocity of loading wall was $2 \times 10^{-6} \mathrm{~m} / \mathrm{step}$. The complete load-strain curve is shown in Figure 3(a), and the breakage of spoils and the distribution of force (the strain of Figures 3(a), 3(b), and 3(c) is 0.08, 0.24, and 0.4 , resp.) are shown in Figures $3(\mathrm{~b})-3(\mathrm{~d})$.

At the beginning of compaction, stage $\mathrm{I}$, as shown in Figure 3(b), there are several force chains across from top to bottom in the centre of spoils. However, these force chains are so weak that the stability of the spoils is unstable, which may lead to dislocation. In other words, the spoils are in a state of seeking for stable interlocking by self-organizing.
With the increasing of load, confining pressure is applied to central spoils by marginal ones. Therefore, the force chains in the centre are apparently stronger than before, and a relative stable interlocking structure is formed.

During loading stage III, the spoils in the centre of sample are highly crushed under the great load, and the porosity decreases as shown in Figure 3(d). In stage III, the compressive properties significantly improve, and strong force chain spreads in central spoils. According to the loadstrain curve (Figure 3(a)), there is a better loadability at lateral stage after large deformation.

According to the above description, it can be seen that the compaction mechanic properties vary in different loading stage.

\section{The Experiment of Unconfined Compaction of Spoils}

3.1. The Gradation Effect on the Loadability of Spoils. The mechanical properties of spoils are influenced not only by the lithology of parent rock, but also the gradation which can be represented by the bulk density. The concept curve of the ideal gradation that could produce the best mechanical performance was firstly developed by Fuller and Thompson [19]. This theory is called Fuller's theory which can be expressed as

$$
p_{i}=100 \sqrt{\frac{d_{i}}{D}},
$$

where $p_{i}$ is the quality percentage of particle whose size is not more than $d_{i}$ and $D$ is the maximum particle size. 


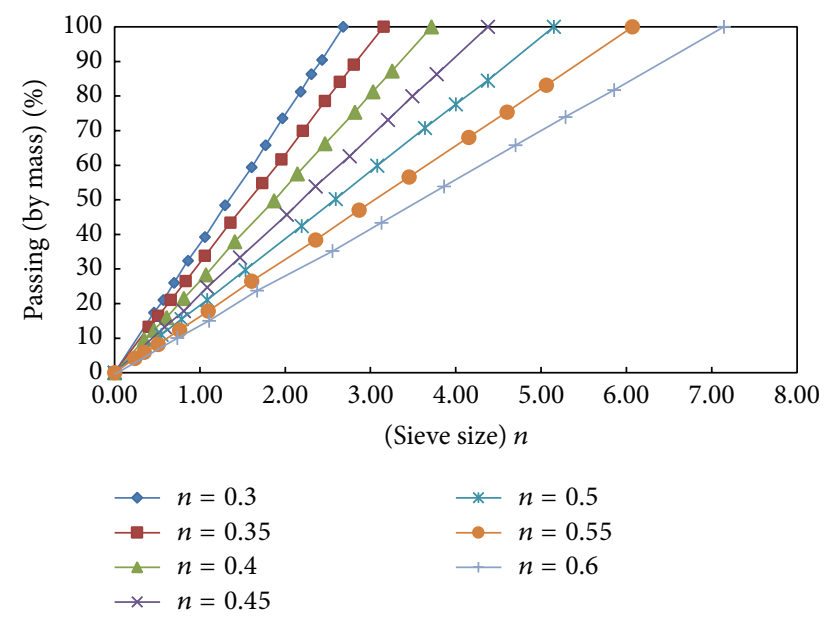

FIGURE 4: Talbot's grading curve maximum density lines (for various $n$ values) for $19.0 \mathrm{~mm}$ nominal maximum size.

In 1923 Talbot and Richart developed the equation for the maximum density line as shown by (7) for concrete mixtures [20]:

$$
p_{i}=100\left(\frac{d_{i}}{D}\right)^{\varphi}
$$

where $\varphi$ is the grading index.

It was further developed and validated for various aggregate types for asphalt mixtures [21], and the Asphalt Institute since the 1980s. The only individual aggregate property required to be input for this technique is the particle size distribution. For over 50 years, the 0.45 Power Chart (produced by using the Talbot's Grading Curve with an $\varphi$ value of 0.45 ) has been the method standardized by the Federal Highway Administration (FHWA) for designing aggregate gradations for the hot mix asphalt industry since the 1960s [21]. The maximum density line starts from the origin and continues to the maximum sieve size. By using the passing rate as the $y$ values and grading index $\varphi$ as the $x$-values, Talbot's grading curve maximum density lines (for various $\varphi$ values) for $19 \mathrm{~mm}$ nominal maximum size were as shown in Figure 4 [21].

It is considered that the compactness is better when $\varphi$ fails in a range between 0.3 and 0.6. In the following experiments, the spoils with single and Talbot's gradations are tested for comparing the loadability.

3.2. Experimental Materials and Method. In this research, the gangue was taken from the stope of a coal mine in Chongqing, China; its lithology is argillaceous sandstone. In order to acquire granular spoils, the gangue was broken and sifted by sieves into seven continuous size ranges in the laboratory. The particle sizes of single gradations are 5-10 mm, 10-16 mm, 16$20 \mathrm{~mm}, 20-25 \mathrm{~mm}, 25-31 \mathrm{~mm}, 31-40 \mathrm{~mm}$, and $40-50 \mathrm{~mm}$. The above preparing process of testing material is shown in Figure 5.

It is known that the crushed spoils without any confining pressure tend to expand horizontally. In order to adapt such movement, spoils were separately put into woven bags

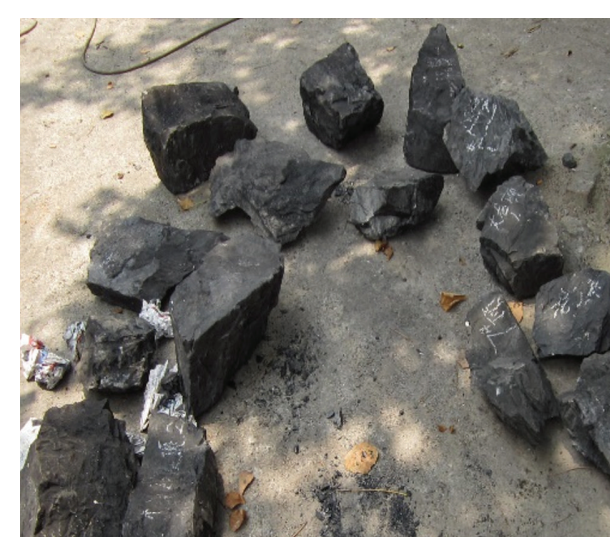

(a)

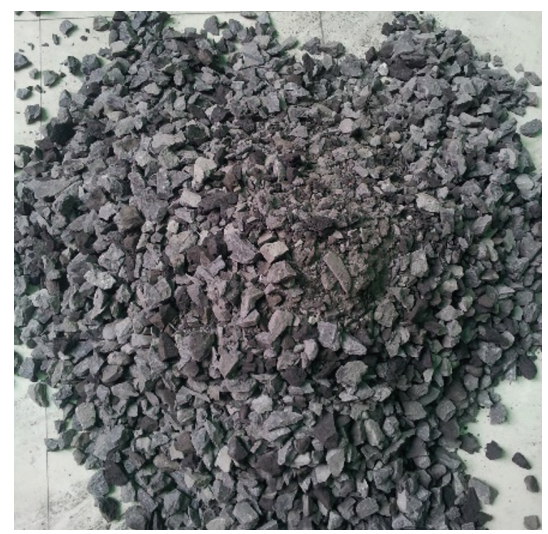

(b)

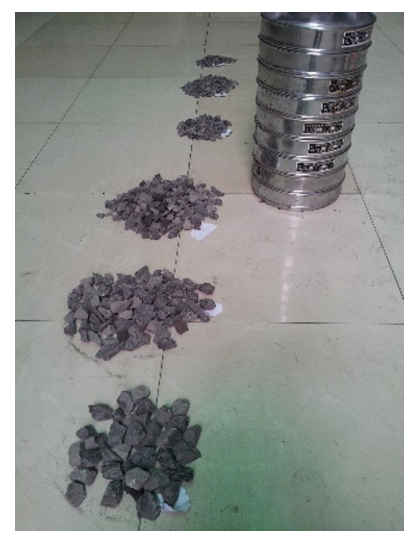

(c)

FIGURE 5: The preparation of gradual spoils in different size ranges: (a) massive gangue; (b) crushed spoils; (c) spoils in different gradations.

according to particle dimensions and sealed at the start of the test. Each bag was a specimen which had single gradation. Based on (7), weight of spoils in every size ranges was calculated and weighted when $\varphi$ is equal to $0.3,0.4$, and 0.5 and the maximum size of spoils was $40 \mathrm{~mm}$. The mixture of them is a specimen with Talbot's gradation. In order to keep consistency, the specimens had a uniform size $(30 \mathrm{~cm} \times 30 \mathrm{~cm} \times 24 \mathrm{~cm})$, as shown in Figure 6 . Then the seven specimens with single gradations and three specimens 


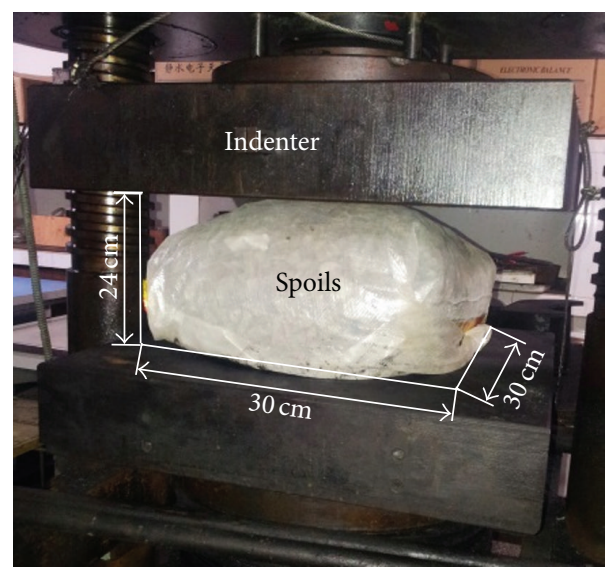

FIGURE 6: Unconfined compressing experiment of spoils.

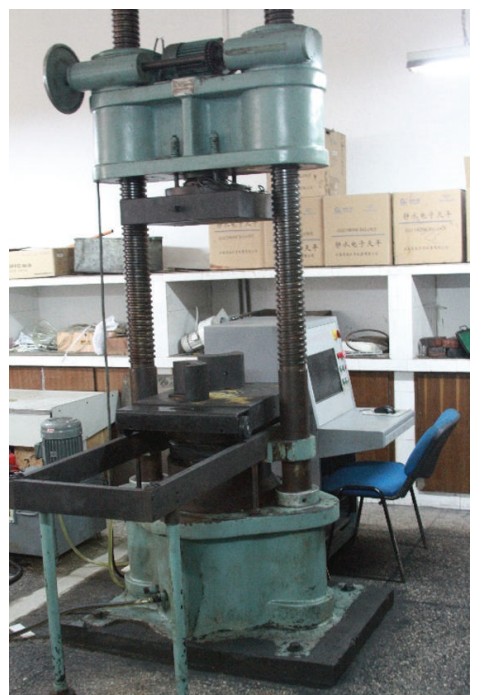

(a)

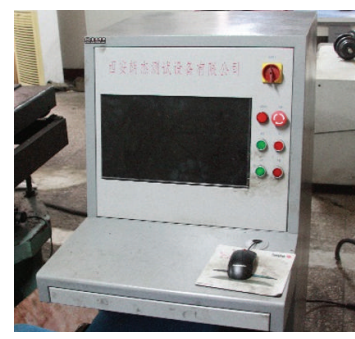

(b)

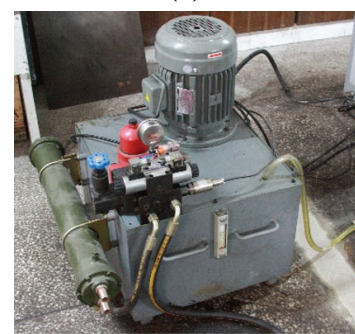

(c)
FIGURE 7: (a) Material compaction test machine; (b) data acquisition system; (c) hydraulic pressure system.

with different grading indexes of spoils are compressed. The material test machine (Y1-76026) which was made in Changchun, China, was used in this experiment (Figure 7). Furthermore, it should be noted that the strength and stiffness of woven bag is small when compared with spoil sample. Therefore, the influence of bag on the loadability of spoil samples can be ignored in the tests.

3.3. Experiment Results. Since horizontal expansion commonly took place during compaction, the area of contact face between indenter and specimens was continually changing. So the stress cannot be calculated accurately. In this paper, load-strain curve is used to describe the loadability of spoils hereafter. The complete load-strain curves of specimen with single gradation under unconfined compression are typically shown in Figure 8(a).

It can be seen from Figure 8(a) that the load is relatively low at the beginning of compression, while there is large

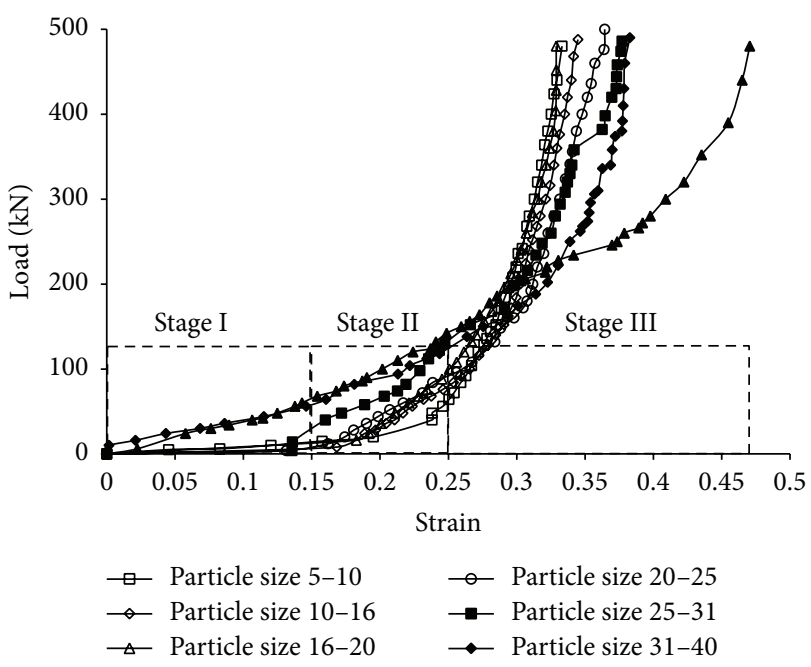

(a)

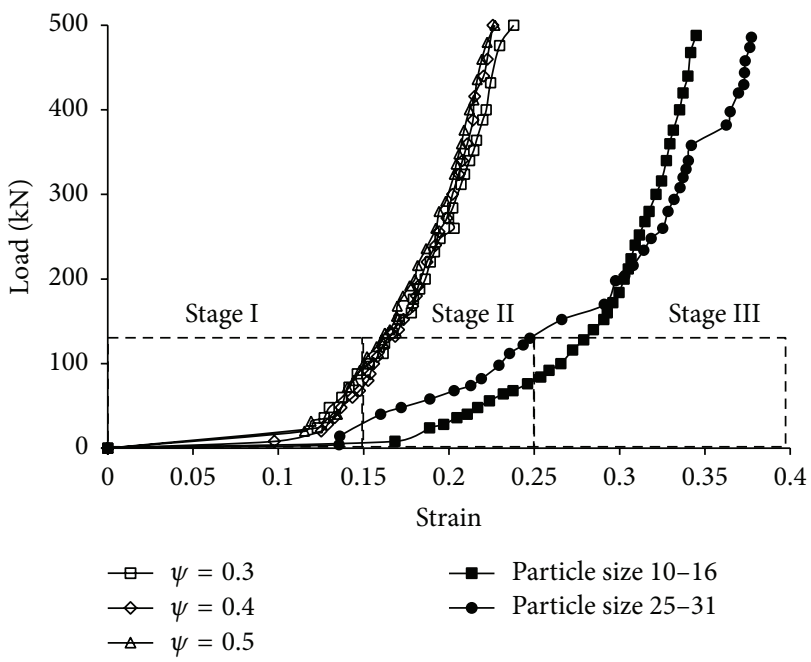

(b)

FIGURE 8: The complete load-strain curves of spoil samples: (a) single gradation; (b) Talbot's gradation.

deformation before specimen reaches a better loadability, for instance, in stages I and II. Moreover, also in the first two stages, the force of smaller spoils is lower than bigger ones under the same strain. This difference can be attributed to the fact that a large number smaller spoils are harder to form an overall stable state, while the bigger spoils are relatively easier to form a stable interlocking structure. However, the load of smaller spoils increases faster than bigger ones in stage III due to the corner and particle breakage of large spoils. This phenomenon is essentially caused by size effect. In addition, it can be found that there is a mutation on stage III of particle size $25 \mathrm{~mm}-31 \mathrm{~mm}$. The most likely reasons are as follows: (1) the instability of hydraulic pressure system of test machine; (2) the break of specimen. By comparing with other curves; we think the first reason has a larger possibility. This mutation caused about 0.02 error in strain. It was relatively small which could be ignored. 


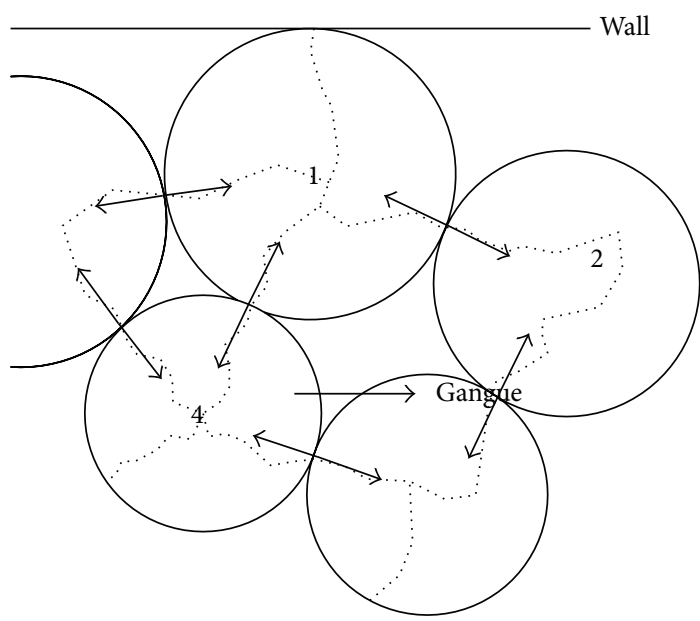

(a)

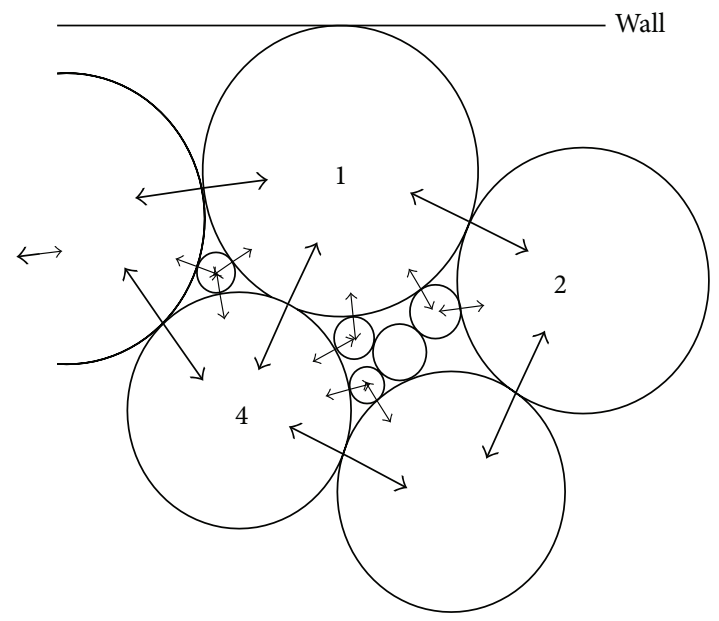

(b)

FIgURE 9: Stress schematics of spoil samples with (a) single gradation and (b) Talbot's gradation.

The load-strain curves of three spoil specimens with Talbot's gradation are shown in Figure 8(b). The loadability of the three different Talbot's index spoil samples is similar to each other. Comparing with single gradation specimens, the load increasing rate of spoils with Talbot's gradation are significantly greater, and the strain in stage I decreased a lot.

The stress schematics of spoils with single gradation and Talbot's gradation are shown in Figure 9. The load bearing structure of the spoils with single gradation is mainly because of interlocking among large ones (Figure 9(a)). Such structure easily deforms under low force, and spoils break into smaller pieces to fill the gap with the increasing of load. For spoils with Talbot's gradation, the space between larger particles is filled by small spoils (Figure 9(b)). Such gradation ends in greater density of specimen. The bearing structure is close to triaxial stress state and the stability is better than single gradation samples.

It is considered that, for materials with greater density, a larger amount of compaction energy is received to achieve the required density criteria. The accumulation of energy results in a high degree of particle breakage. The effect of increased interlocking leads to force raising. When the inner stress exceed the strength, the loadability generally falls with particle breakage under a given density. In this case, however, it implies that the friction angle for a given density can increase with particle breakage under varying gradations. This is due to the higher levels of densification generated by greater amounts of particle breakage.

\section{Discussions}

The comparison and discussion of numerical and experimental results are presented in this section. According to the numerical modelling and the compaction experiments, it can be found that the loading characteristics of granular spoils under unconfined compression have spatial and temporal characteristics. The detailed description is as follows.
4.1. The Force Evolution of Granular Spoils under Unconfined Compression. The variety of loadability and breakage in different space and time are mainly caused by the force state evolution of spoils. So the force state can be used to reflect the spatial-temporal mechanical behaviour of spoils. The forces applied on spoils are $\sum \bar{F}_{s}$ (the shear stress which leads to dislocation), $\sum \bar{F}_{n}$ (the normal force which is caused by the extrusion of spoils), $\sum \bar{f}$ (the friction force), and $\sum \bar{F}_{n}^{\prime}$ (the normal reaction force). According to the difference of loading status and static relationship, the force states of spoils under free compaction can be divided into three types:

(1) When $\sum \bar{F}_{s}>\sum \bar{f}$, there is only rigid moving of spoil.

(2) When $\sum \bar{F}_{s}=\sum \bar{f}$, besides, the shear and normal stress are both less than peak strengths; the force in spoils achieves an equilibrium state.

(3) When $\sum \bar{F}_{s}=\sum \bar{f}$, moreover, the shear or normal stress is greater than peak strength; the spoils will break.

The different force states of spoils result in the change of loadability. This is also the reason for the loading capability of spoils which tends to have spatial and temporal characteristics under compaction.

4.2. The Temporal Loading Characteristic. The best-fit curves of experimental data are presented as follows:

$$
\begin{array}{ll}
N\left(s_{5-10}\right)=0.1974 \exp (23.34 \varepsilon), & R^{2}=0.9991, \\
N\left(s_{10-16}\right)=0.4673 \exp (20.15 \varepsilon), & R^{2}=0.9974, \\
N\left(s_{16-20}\right)=0.6638 \exp (19.59 \varepsilon), & R^{2}=0.9852, \\
N\left(s_{20-25}\right)=1.359 \exp (16.24 \varepsilon), & R^{2}=0.9943, \\
N\left(s_{25-31}\right)=8.809 \exp (10.78 \varepsilon), & R^{2}=0.9917, \\
N\left(s_{31-40}\right)=7.904 \exp (10.37 \varepsilon), & R^{2}=0.9746,
\end{array}
$$




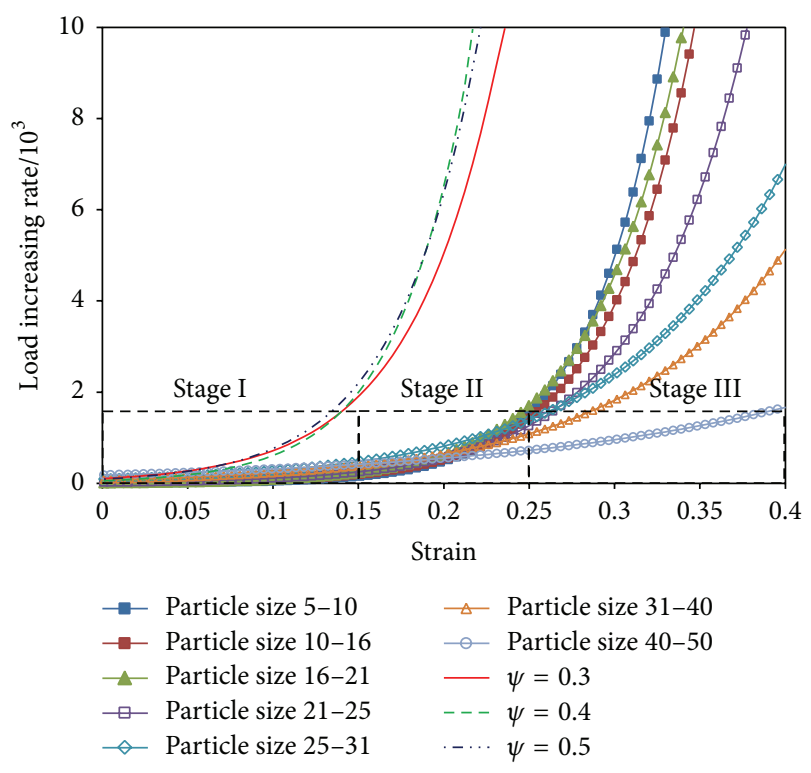

(a)

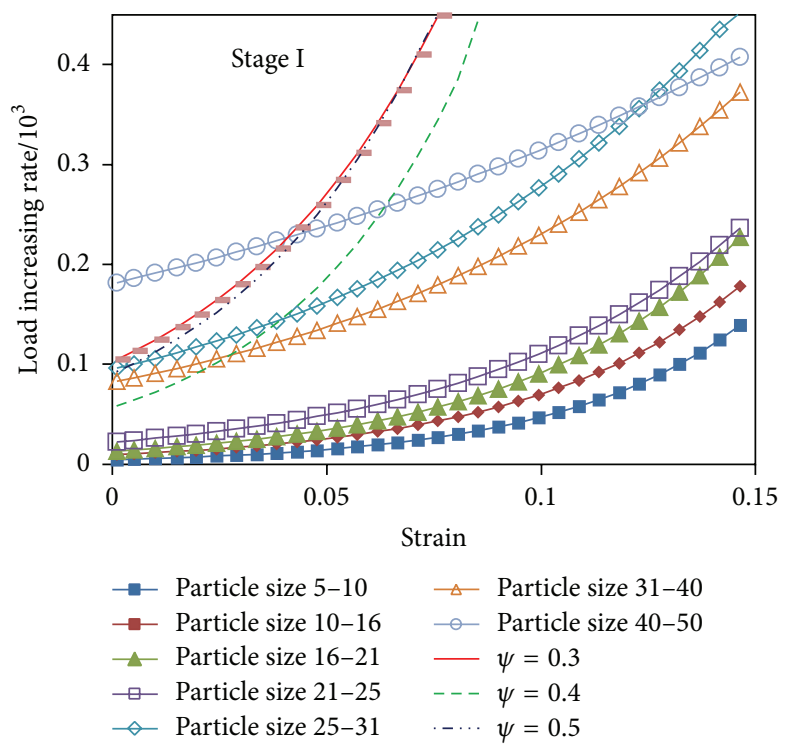

(b)

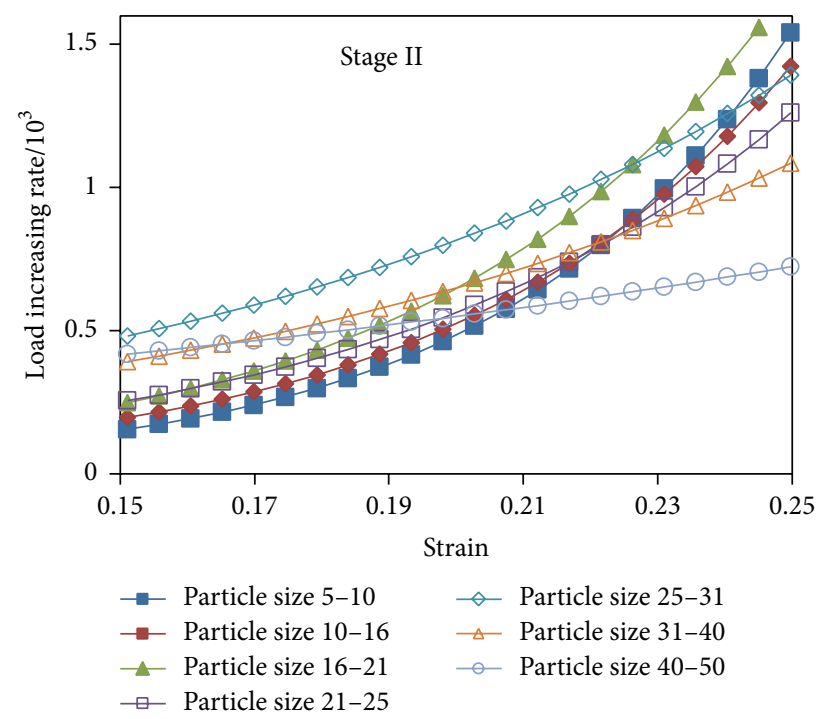

(c)

FIGURE 10: The fitting curve of load increasing rate.

$$
\begin{array}{ll}
N\left(s_{40-50}\right)=32.45 \exp (5.574 \varepsilon), & R^{2}=0.9762, \\
N\left(s_{\varphi=0.3}\right)=5.238 \exp (19.54 \varepsilon), & R^{2}=0.9887, \\
N\left(s_{\varphi=0.4}\right)=2.404 \exp (23.76 \varepsilon), & R^{2}=0.9935, \\
N\left(s_{\varphi=0.4}\right)=4.254 \exp (21.32 \varepsilon), & R^{2}=0.9919,
\end{array}
$$

where $N$ is load; $\varepsilon$ is axial strain; $S_{i}$ is the range of particle size.

According to (8), the load-strain relationship can be defined by the following equation:

$$
N\left(S_{i}\right)=a \cdot \exp (b \varepsilon),
$$

where $a$ is the loading factor; $b$ is the strain factor.
By taking the derivative of (9), the curve of load increasing rate of spoils can be obtained:

$$
\left.N \dot{(} S_{i}\right)=a b \cdot \exp (b \varepsilon)
$$

where $N\left(S_{i}\right)$ is the load increasing rate of spoils in different particle size. The simulated curve of $N\left(S_{i}\right)$ is shown in Figure 10.

It can be seen from Figure 10(a) that the slope of curves varies with the increase of strain, and it is affected by particle sizes. Accordingly, the whole process of compaction can be divided into three stages.

(1) When $\varepsilon<0.15$, the $N\left(S_{i}\right)$ of smaller spoils is less than larger ones (Figure 10(b)). The formation of interlocking structure in spoils enhances its load bearing capacity. During 


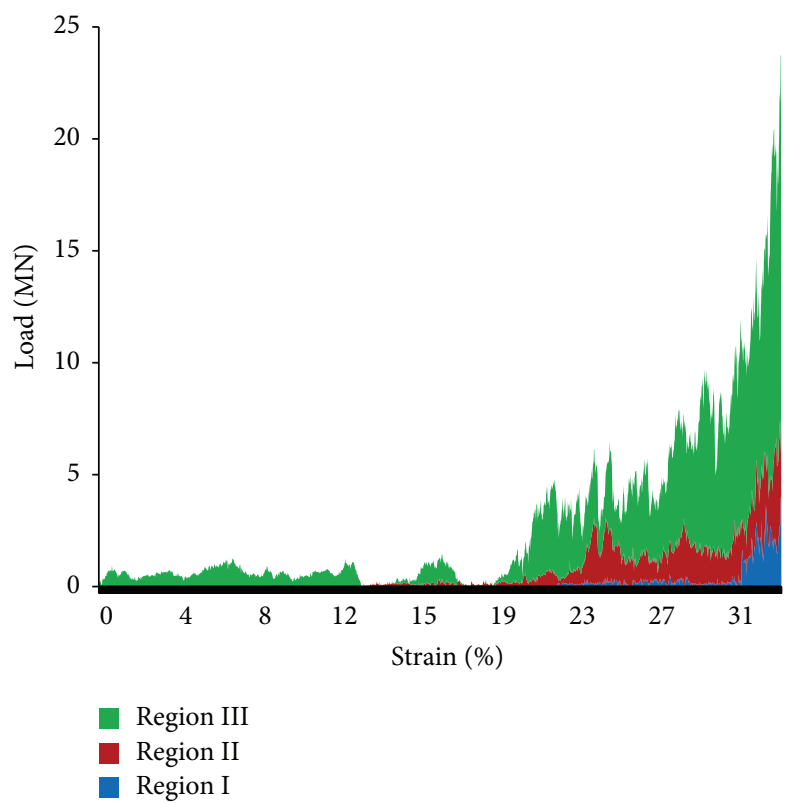

(a)

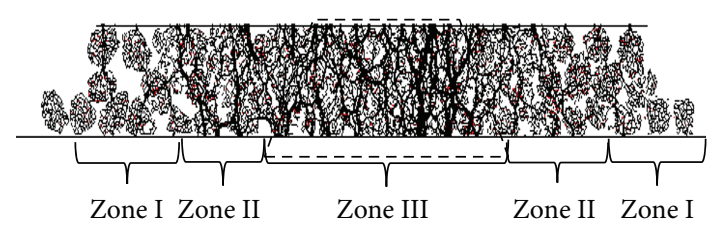

(b)

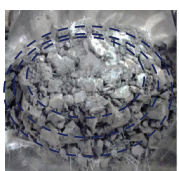

(1)

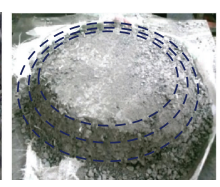

(2)

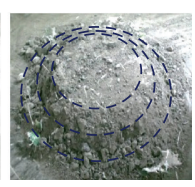

(3) (c)

FIGURE 11: The spatial characteristic of spoils under unconfined compression and the comparison of the consolidated zones. (1) Large particle size; (2) small particle size; (3) Talbot' gradation.

this stage, the spoils are in the (1) force state. The force chain in spoils has a simple structure and is still in low level. During this stage, move and rotate are the main deformation type of spoils. This stage (stage I) can be called rearranging stage as the spoils are searching for stable interlocking and dislocation occurs during this stage.

(2) When $0.15<\varepsilon<0.25$, the $N\left(S_{i}\right)$ of spoils with smaller size gradually becomes greater than larger ones, as shown in Figure 10(c). The central spoils form a stable carrying structure; namely, the spoils are in the (2) force state. In this stage, due to the confining pressure applied by outer spoils, the stability of structure increases from edge to centre. With the increase of load, the deviatoric stress gradually exceeds the peak strength and the porosity decreases due to the break of spoils. This stage can be called breaking stage (stage II).

(3) When $\varepsilon>2.5$, there is a surge in load; the $N\left(S_{i}\right)$ of smaller spoils is greater. During this stage, the central spoils sufficiently break. Such breakage results in the gradation changes. Smaller pieces fill the space and consolidate with larger ones under high pressure. The loadability of spoils enhances significantly. This stage can be defined as consolidated stage (stage III) in this study.

It also can be seen from Figure 10 that the $\left.N \dot{\left(S_{i}\right.}\right)$ of Talbot's gradation during the stage I can reach the level of single gradation's in stage III. So it can be recommended that Talbot's gradation is better to be used in field application.

4.3. The Spatial Characteristic of Spoils under Unconfined Compression. In addition to the loadability variation with time, the spoils also tend to have spatial variation characteristic under unconfined compression. When the spoils are in stage II or III, different parts of specimen have various density and loadability. According to the force state of spoils, it can be divided into three zones. The zones distribute as concentric circular, from outside to inside; these zones can be defined as follows: I, rearranging zone; II, breaking zone; III, consolidating zone, as shown in Figures 11(a) and 11(b). The carrying properties of the zones are, respectively, similarly to the three stages of spoils under compaction. The load-strain curve of the three parts is shown in Figure 11(a).

The spoils in zone I are compacted in very low confining pressure, so they are easily dislocated and rearranged which ends in large deformation. For the spoils in zone II, it is under confining pressure applied by zone I, so the stability of carrying structure increases and the loadability significantly improves. By the act of greater confining force and axial load, there is a higher degree of particle breakage that occurs on particles of zone III. This situation results in reduction of 
porosity and increase of density. The fragments of various sizes solidify and form the consolidated zone where the loadability of relevant spoils further improved (Figure 11(b)).

4.4. The Comparison of Consolidating Zone. In order to observe the consolidating zone, the loose spoils on the edge of specimens are stripped after the compaction experiments. It can be found that the spoils strongly consolidated in central part (zone III). The shape of zone is circular truncated cone with a high magnitude in density (Figure $11(\mathrm{c})$ ). The spoils in this zone are highly broken, which experienced repetitively process of crushing and consolidation. For the same kind of rock materials, the density of the consolidated zone is the leading factor influencing the load bearing capacity of spoils. The density of spoils with smaller particle size is greater, and the porosity is less, tending to be easier to be compacted. Conversely, the larger the particle size is, the lower the density is. This can also explain the difference in loadability of spoils with various particle sizes.

\section{Conclusions}

In this research, numerical simulation and a series of laboratory experiments were carried out to study the unconfined compressive behaviour of spoils with different gradations for coal mine backfill. In numerical study, the particles were assembled in PFC according to the real shape of spoils which is obtained by image technique. Basing on the profile of spoils, numerical model was built and then compressed by the wall. Such method was proved to be consistent with physical experiments.

The compaction of simulation and experiments indicated that the load-strain behaviour of spoils was nonlinear and load-dependent. The complete load-strain process can be divided into three stages: rearranging stage (stage I); breaking stage (stage II); and consolidating stage (stage III). Stage I is characterized by large deformation and weak loadability; during stage II, spoils have formed stable interlocking structure and the rate of mechanics improves rapidly. In zone III, the central spoils highly crushed and consolidated, and its load bearing capacity increases fastest during this stage.

In addition, the gradation has a marked impact on the load-strain behaviour of spoils. During stage I, Ni $\left.S_{i}\right)$ of smaller spoils is relatively low, but it increases faster than larger ones in stages II and III. The load increasing rate of spoils with Talbot's gradation is greater than single gradation's.

In addition, the spoils under unconfined compression also have spatial characteristic. According to the force state, the spoils can be divided into three zones: rearranging zone (zone I); interlocking zone (zone II); and consolidating zone (zone III) from outside to inside. Among them, the consolidating zone has the highest value of density, so it is the main part to bear the overlying strata weight. Clearly, the uniaxial compressive strength of the parent rock constitutes one of the significant elements in determining the load behaviour of spoils.

\section{Conflict of Interests}

The authors declare that there is no conflict of interests regarding the publication of this paper.

\section{Acknowledgments}

The authors gratefully acknowledge funding by National Natural Science Foundation Project of China (51474039, 51404046, and U1361205), Scientific Research Foundation of State Key Laboratory of Coal Mine Disaster Dynamics and Control (2011DA105287-ZD201302, 2011DA105287-ZD201302, and 2011DA105287-MS201403), Fundamental Research Funds for the Central Universities (106112015CDJXY240003), and Program Supported by the Basic Research of Frontier and Application of Chongqing (cstc2015jcy jA90019).

\section{References}

[1] M. Hitch, S. M. Ballantyne, and S. R. Hindle, "Revaluing mine waste rock for carbon capture and storage," International Journal of Mining, Reclamation and Environment, vol. 24, no. 1, pp. 64-79, 2010.

[2] P. Michalski and K. M. Skarzynska, "Compactability of coalmining wastes as a fill material," in Proceedings of the 4th International Symposium on the Reclamation, Treatment and Utilization of Coal Mining Wastes, pp. 283-288, Durham, UK, 1984.

[3] F. W. Solesbury, "Coal waste in civil engineering works: two case histories from South Africa," in Proceedings of the 2nd International Symposium on the Reclamation, Treatment and Utilization of Coal Mining Waste, A. K. M. Rainbow, Ed., pp. 207-218, London, UK, September 1987.

[4] Z. Q. Jiang, L. J. Ji, and R. S. Zuo, "Research on mechanism of crushing-compression of coal waste," Journal of China University of Mining \& Technology, vol. 30, no. 2, pp. 139-142, 2001.

[5] Z. W. Qian, W. L. Cao, and Z. Q. Jiang, "Experimental study on confined loading-water immersion-unloading of coal spoil," Journal of Mining \& Safety Engineering, vol. 30, pp. 579-584, 2013.

[6] D.-S. Lee, K.-Y. Kim, G.-D. Oh, and S.-S. Jeong, "Shear characteristics of coarse aggregates sourced from quarries," International Journal of Rock Mechanics and Mining Sciences, vol. 46, no. 1, pp. 210-218, 2009.

[7] C. D. Su, M. Gu, X. Tang, and W. B. Guo, "Experiment study of compaction characteristics of crushed stones from coal seam roof," Chinese Journal of Rock Mechanics and Engineering, vol. 31, no. 1, pp. 18-26, 2012.

[8] Z. G. Ma, R. X. Gu, Z. M. Huang, G. Peng, L. Zhang, and D. Ma, "Experimental study on creep behavior of saturated disaggregated sandstone," International Journal of Rock Mechanics and Mining Sciences, vol. 66, pp. 76-83, 2014.

[9] X.-X. Miao, J.-X. Zhang, and M.-M. Feng, "Waste-filling in fully-mechanized coal mining and its application," Journal of China University of Mining and Technology, vol. 18, no. 4, pp. 479-482, 2008.

[10] J. X. Zhang, Study on Strata Movement Controlling Raw Waste Backfilling with Fully Mechanized Coal Wining Technology and Its Engineering Application, China University of Mining and Technology, Beijing, China, 2004. 
[11] Z. N. Zhang, X. B. Mao, and X. R. Ge, "Testing study on compressive modulus of loose rock blocks under confining constrain," Chinese Journal of Rock Mechanics and Engineering, vol. 23, no. 18, pp. 3049-3054, 2004.

[12] C. A. Tang, X. H. Xu, S. Q. Kou, P.-A. Lindqvist, and H. Y. Liu, "Numerical investigation of particle breakage as applied to mechanical crushing - part I: single-particle breakage," International Journal of Rock Mechanics and Mining Sciences, vol. 38, no. 8, pp. 1147-1162, 2001.

[13] N. Bahrani, P. K. Kaiser, and B. Valley, "Distinct element method simulation of an analogue for a highly interlocked, nonpersistently jointed rockmass," International Journal of Rock Mechanics and Mining Sciences, vol. 71, pp. 117-130, 2014.

[14] I. Tomac and M. Gutierrez, "Fluid lubrication effects on particle flow and transport in a channel," International Journal of Multiphase Flow, vol. 65, pp. 143-156, 2014.

[15] B. Indraratna, N. T. Ngo, C. Rujikiatkamjorn, and S. W. Sloan, "Coupled discrete element-finite difference method for analysing the load-deformation behaviour of a single stone column in soft soil," Computers and Geotechnics, vol. 63, pp. 267-278, 2015.

[16] S. Bock, "Impact of shaft steelwork on grain size distribution of filling material during shaft closure based on the DEM simulations," Engineering Structures, vol. 84, pp. 102-119, 2015.

[17] D. O. Potyondy and P. A. Cundall, "A bonded-particle model for rock," International Journal of Rock Mechanics \& Mining Sciences, vol. 41, pp. 1329-1364, 2004.

[18] D. O. Potyondy, "The bonded-particle model as a tool for rock mechanics research and application: current trend sand future directions," in Proceedings of the 7th Asian Rock Mechanics Symposium, pp. 73-105, Seoul, Republic of Korea, October 2012.

[19] W. B. Fuller and S. E. Thompson, "The laws of proportioning concrete," Transactions of the American Society of Civil Engineers, vol. 59, pp. 67-143, 1906.

[20] AN. Talbot and FE. Richard, The Strength of Concrete-Its Relation to the Cement, Aggregates and Water, University of Illinois, Champaign, Ill, USA, 1923.

[21] A. C. Majella, Optimization of Aggregate Gradation Combinations to Improve Concrete Sustainability, University of Toronto, Toronto, Canada, 2011. 

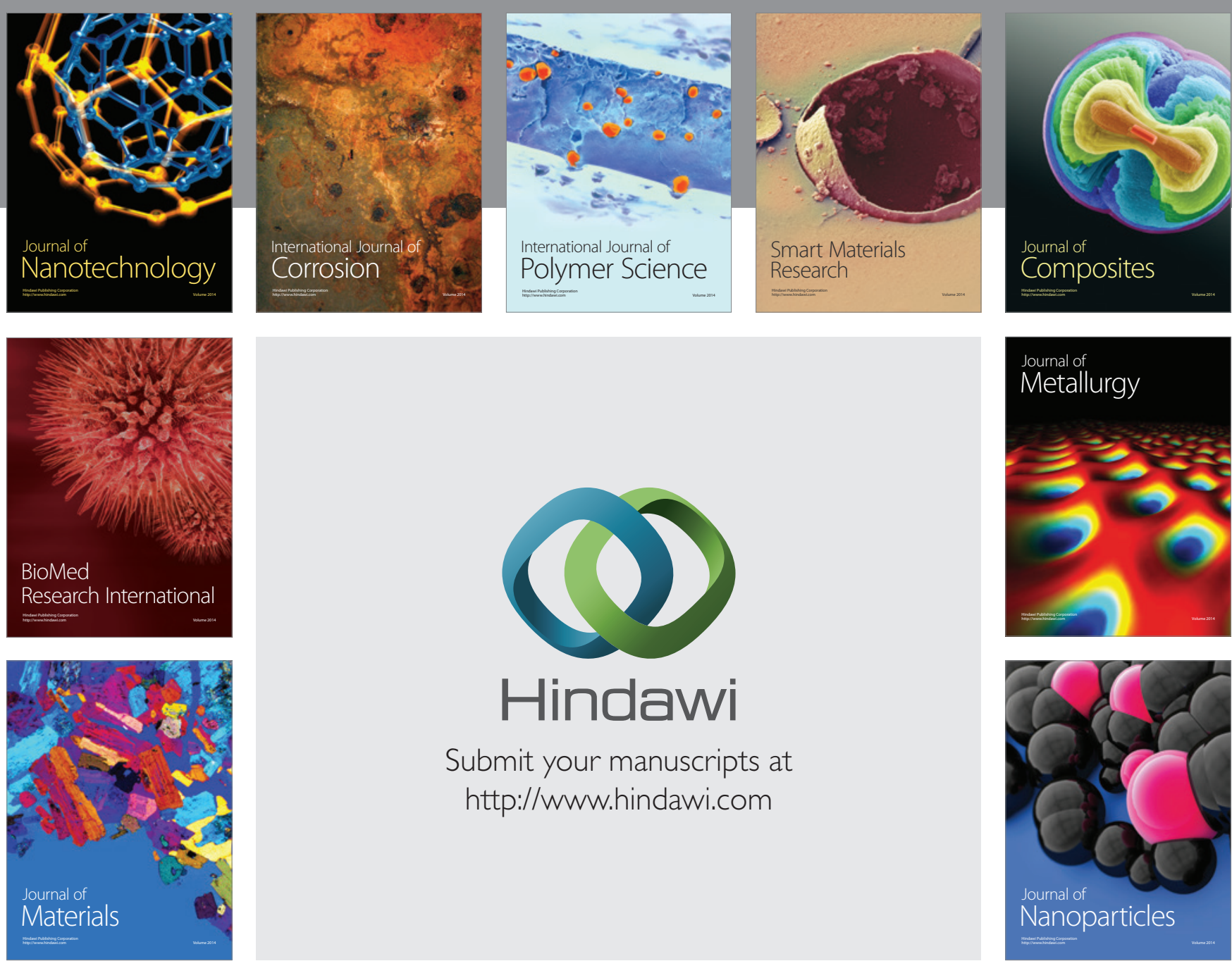

\section{Hindawi}

Submit your manuscripts at

http://www.hindawi.com

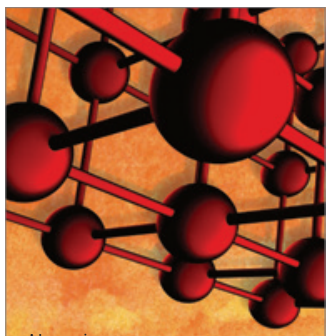

Materials Science and Engineering
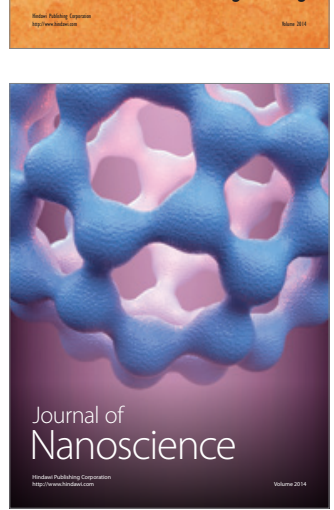
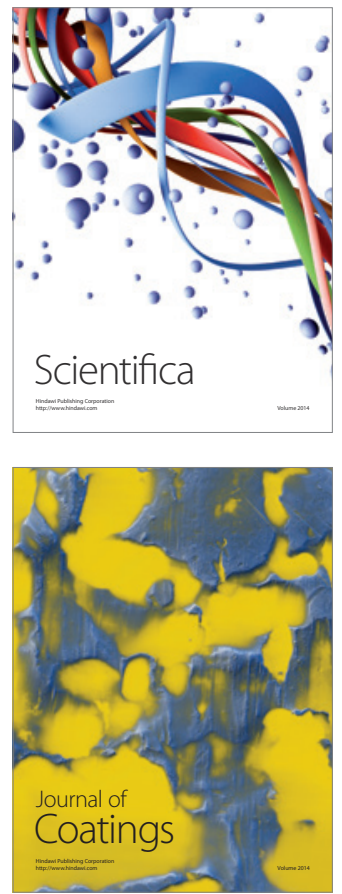
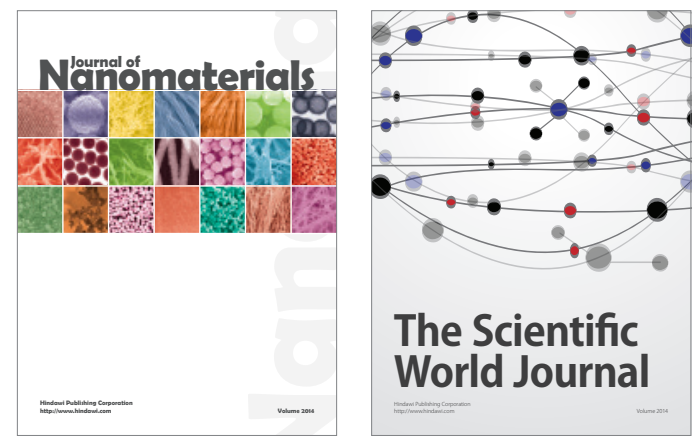

The Scientific World Journal
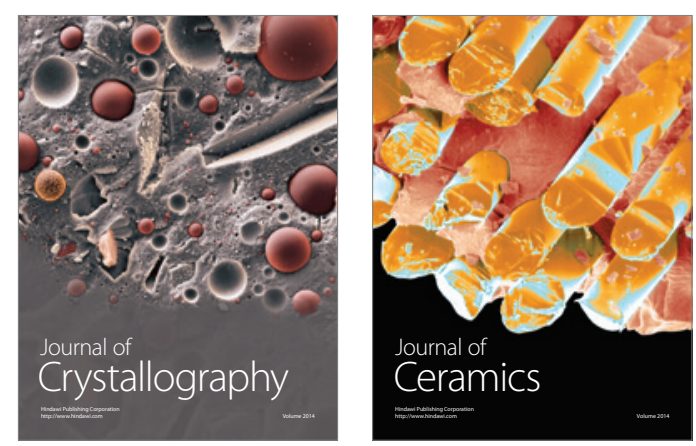
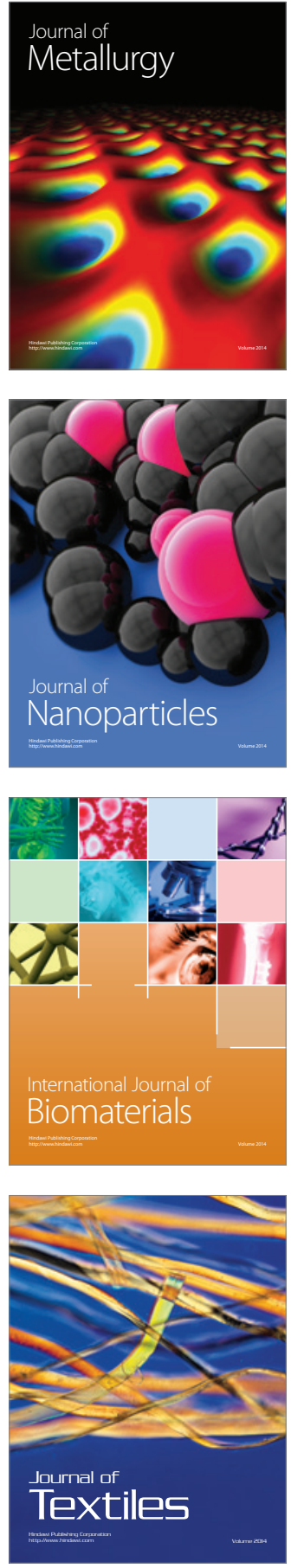